\title{
Surgical Outcomes and Correlation of the Copenhagen Neck Functional Disability Scale and Modified Japanese Orthopedic Association Assessment Scales in Patients with Cervical Spondylotic Myelopathy
}

\author{
Shirzad Azhari, Parisa Azimi, Sohrab Shazadi, Hamid Khayat Kashany, \\ Hossein Nayeb Aghaei, Hassan Reza Mohammadi \\ Functional Neurosurgery Research Center, Shahid Beheshti University of Medical Sciences, Tehran, Iran
}

\begin{abstract}
Study Design: Cross-sectional.
Purpose: Clinical outcome study comparing the Copenhagen Neck Functional Disability Scale (CNFDS) and modified Japanese orthopedic association (mJOA) assessment scales in patients with cervical spondylotic myelopathy (CSM).

Overview of Literature: Comparison of instruments that measure patient-reported outcomes is needed.

Methods: A cross-sectional analysis was conducted. Ninety five patients with CSM were entered into the study and completed the CNFDS and the mJOA preoperatively and postoperatively. Correlation between the CNFDS and the mJOA was evaluated preoperatively and at the end of follow-up. Responsiveness to change of CNFDS and mJOA was also assessed. Clinical outcomes were also measured with the recovery rate of $\mathrm{mJOA}$ score at end of follow-up.

Results: The mean age of patients was 58.2 (standard deviation, $S D=8.7$ ) years. Mean follow-up was 2.1 years (range, 1 to 4 years). The mJOA correlated strongly with the CNFDS score preoperatively and postoperatively $(r=-0.81$ and -0.82 , respectively; $p<0.001)$. The CNFDS and the mJOA were able to detect changes after the surgery $(p<0.001)$. The mean mJOA recovery rate was $51.8 \%$ $(S D=13.1 \%)$.

Conclusions: Surgery for the treatment of patients with CSM is an efficacious procedure. CNFDS and mJOA scores have a strong correlation in measuring disability among CSM patients.
\end{abstract}

Keywords: Copenhagen Neck Functional Disability Scale; Modified Japanese orthopedic association; Cervical spondylotic myelopathy; Clinical outcome

\section{Introduction}

Cervical spondylotic myelopathy (CSM) refers to the im- paired function of the spinal cord caused by degenerative changes of the discs and facet joints in the cervical spine. It includes cervical herniated disc (CHD) and cervical

\footnotetext{
Received Sep 19, 2015; Revised Oct 25, 2015; Accepted Oct 25, 2015

Corresponding author: Parisa Azimi

Shohada Tajrish Hospital, Functional Neurosurgery Research Center of Shohada Tajrish Hospital,

Shahid Beheshti University of Medical Sciences, Tehran, Iran

Tel: +98-2122749204 Fax: +98-2188265188, E-mail: parisa.azimi@gmail.com
} 
spinal stenosis (CSS), and is a progressive spine disease. CSM symptoms depend on the level(s) of the spinal cord involvement and its pattern [1].

The variety of measures to evaluate CSM and disability for clinical or research purposes include the neck disability index (NDI) [2], northwick park neck pain questionnaire [3], Copenhagen Neck Functional Disability Scale (CNFDS) [4], neck pain and disability scale (NPAD) [5], Bournemouth questionnaire for neck pain (BQN) [6], patient-specific functional scale [7], modified Japanese Orthopedic Association (mJOA) criteria [8,9], Japanese Orthopaedic Association Cervical Myelopathy Evaluation Questionnaire (JOACMEQ) [10], Nurick-score [11,12], Japanese Orthopaedic Association (JOA) score [13], Cooper-myelopathy-scale [14], Proloscore [15], Europeanmyelopathy-score [16] and the CNFDS [17]. However, it is argued that none of these measures can be considered as a golden standard $[15,18]$. In addition, each measure has advantages and disadvantages.

This paper explores the use of the CNFDS and the mJOA tools that have been validated for specific conditions. It is unclear whether these two functional scoring systems provide similar evaluations of patients with CSM. Hence, the purpose of this study was surgical outcome assessment and to determine the correlation between the CNFDS and the mJOA scales before and after surgery in patients with CSM.

\section{Materials and Methods}

\section{Patients and data collection}

The final draft of the Iranian versions of the CNFDS and mJOA were administered to a sample of newly diagnosed CSM patients attending the neurosurgery clinic of a large teaching hospital in Tehran, from April 2007 to June 2013. CSM was diagnosed on the basis of appropriate history, clinical examination, and investigations, notably magnetic resonance imaging or computed tomography (CT) scan of the cervical spine. There were no restrictions on patient selection with regard to types of CSM, age or other characteristics. The exclusion criteria were prior cervical spine surgery or other coexisting pathology that might result in functional impairment. All patients had the typical symptoms of CSM and were surgical candidates.

\section{Surgery procedure}

The key to the treatment of the CSM is to remove the pressure from the spinal cord. Surgical methods to decompress the spinal cord included three approaches: (1) from the front of the neck as anterior cervical discectomy and fusion, anterior cervical corpectomy, and (2) from the back of the neck as cervical laminectomy, cervical laminectomy and fusion, cervical laminoplasty, and (3) a combined procedure [19]. All three approaches were applied to the patients.

\section{CNFDS}

The CNFDS (Appendix 1) is designed to evaluate the disability experienced by CSM patients. It is a selfadministered questionnaire that consists of three sections including 15 items that evaluates the impact of neck pain including the patient's perception of the future impact of neck pain (3 items including 1, 5, and 15), disability during everyday activities (9 items including items $2,3,4,5$, $7,8,9,10$ and 12) and social interaction and recreation (5 items including item 6, 9, 11, 13 and 14). Each item has three possible response categories (yes $=0$, occasionally $=1$ and no=2) for the first 5 items and the remaining items are scored in the reverse (yes $=2$, occasionally $=1$ and no $=0$ ). The total score ranges from 0 to 30 , with higher score indicating greater disability [17].

\section{4. $\mathrm{mJOA}$}

The Iranian version of the mJOA was simultaneously administered to patients. It is a self-administered, diseasespecific tool modified from the JOA score $[8,9]$ that consists of four sections including 22 items: motor dysfunction of the upper extremities (6 items), motor dysfunction of the lower extremities (8 items), sensation (4 items) and sphincter dysfunction (4 items). The score the respective section ranges from 0 to 5,0 to 7,0 to 3 and 0 to 3 , giving a total score ranging from 0 to 18 . Higher scores indicate less disability. In this study the total mJOA was calculated for assessment. In a previous study by this group, the Iranian version of mJOA was documented as a reliable and valid measure of motor, sensory and sphincter dysfunctions among CSM patients [9].

Patients were assessed preoperatively and postoperatively. CNFDS and mJOA scoring were completed at the same time on the day before surgery and at the end of follow- 
up. The recovery rate of mJOA score (\%) was also assessed using a previously published formula [20]: recovery rate $(\%)=[$ postoperative score-preoperative score] $/[$ full score (18)-preoperative score $] \times 100$.

\section{Statistical analyses}

Statistical analyses were performed using PASW ver. 18.0 (SPSS Inc., Chicago, IL, USA). A $p$-value of $<0.05$ was considered statistically significant. Correlation between the CNFDS and the mJOA was assessed using Pearson's correlation coefficient. Values of 0.40 or above were considered satisfactory $(r \geq 0.81-1.0$ as excellent, $0.61-0.80$ very good, $0.41-0.60$ good, $0.21-0.40$ fair, and $0.0-0.20$ poor) [21]. CNFDS and the mJOA scores were calculated preoperatively and postoperatively using the paired $\mathrm{t}$-test to capture the changes after surgery.

\section{Ethics}

The Ethics Committee of Shahid Beheshti University of Medical Sciences, Tehran, Iran, approved the study.

\section{Results}

\section{Study sample}

Ninety five patients with CSM were studied. Their mean age was 58.2 (standard deviation, $\mathrm{SD}=8.7$ ) years. The mean symptom duration was 11.6 months (range, 1 to 59 months). The characteristics of patients and their scores on the mJOA are presented in Table 1. Most patients with CSM had a developmental narrow spinal canal, and the decompressive laminae were distributed from $\mathrm{C} 2$ to C7 levels. The number of decompressed lamina was 2.6 $(\mathrm{SD}=1.0)$. Most patients with CHD had a one- or two level discectomy and were distributed from the $\mathrm{C} 2$ to $\mathrm{C} 7$ levels. The anterior approach (discectomy/corpectomy with instrumented fusion; $\mathrm{n}=72$ ), posterior approach (either laminectomy and fusion or laminoplasty; $n=20$ ), and combination of both anterior and posterior approaches $(n=3)$ were performed for decompressive spinal surgery. Statistically differences were observed preoperative and postoperative assessments indicating improvements in outcomes and functionality in all subscales $(p<0.001)$. However, there was no significant difference between patients with CSS and CHD $(p \geq 0.05)$.
Table 1. The characteristics of the study sample $(n=95)$

\begin{tabular}{lc} 
& Number (\%) \\
\hline Age groups (yr) & $58.2(8.7)$ \\
\hline Mean (standard deviation) & $21-78$ \\
\hline Range & \\
\hline Sex & $44(46.3)$ \\
\hline Male & $51(53.7)$ \\
\hline Female & \\
\hline Type of disease & $52(54.7)$ \\
\hline Cervical herniated disc & $43(45.3)$ \\
\hline Cervical spinal stenosis & \\
\hline No. of stenotic levels & $47(49.5)$ \\
\hline 1 & $23(24.2)$ \\
\hline 2 & $25(26.3)$ \\
\hline 3 and more & \\
\hline Type of surgery & $72(75.8)$ \\
\hline Anterior & $20(21.1)$ \\
\hline Posterior & $3(3.1)$ \\
\hline Both anterior and posterior & \\
\hline
\end{tabular}

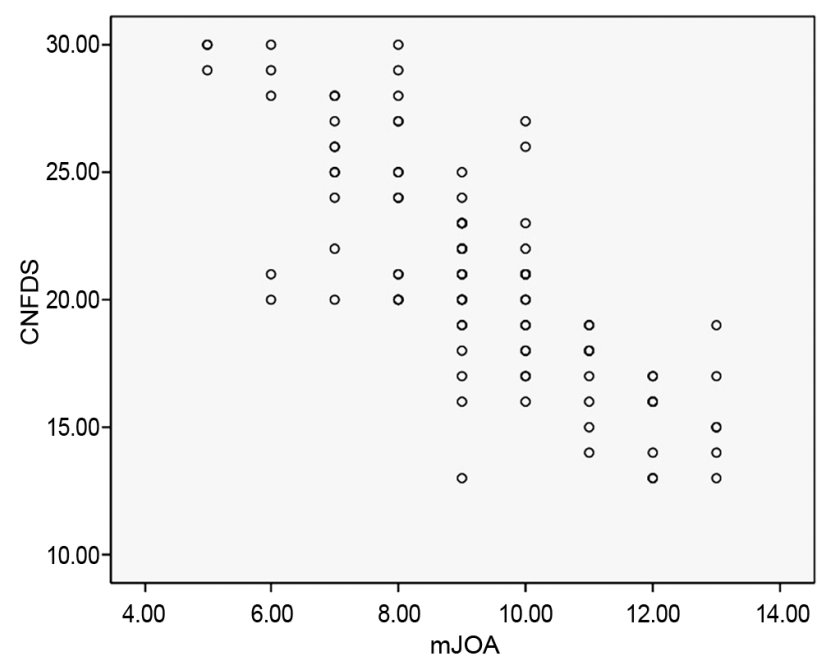

Fig. 1. Total score of the Copenhagen neck functional disability scale (CNFDS) correlates strongly with total score of the modified Japanese orthopedic association (mJOA) preoperatively.

CNFDS total score correlated strongly with mJOA total score preoperatively and at the end of follow-up, lending support to its good convergent validity $(r=-0.81$ and -0.82 , respectively; $p<0.001$ ) (Fig. 1 ). In all instances, CNFDS and mJOA tools were able to detect changes after the intervention (surgery), indicating improvements in all subscales. The outcomes are shown in Tables 2 and 3. The 
Table 2. Responsiveness to change as measured by the copenhagen neck functional disability scale $(n=95)$

\begin{tabular}{lrrr} 
& Preoperative & Postoperative & $p$-value \\
Pain severity & $4.3(1.5)$ & $1.7(1.2)$ & $<0.001$ \\
Disability & $11.4(4.5)$ & $4.9(2.1)$ & $<0.001$ \\
Social interaction & $5.3(1.9)$ & $2.1(1.4)$ & $<0.001$ \\
Total & $21.0(8.1)$ & $8.7(4.5)$ & $<0.001$ \\
\hline
\end{tabular}

Values are presented as mean \pm standard deviation.

${ }^{\text {al }}$ Derived from paired samples $t$-test.

Table 3. Responsiveness to change as measured by the modified Japanese Orthopedic Association scale ( $n=95)$

\begin{tabular}{lccc} 
& Preoperative & Postoperative & $p$-value \\
Motor dysfunction score of the upper extremities & $3.35(1.1)$ & $4.2(0.9)$ & $<0.001$ \\
Motor dysfunction score of the lower extremities & $3.13(1.3)$ & $5.1(1.7)$ & $<0.001$ \\
Sensation & $1.21(0.9)$ & $2.0(0.9)$ & $<0.001$ \\
Sphincter dysfunction & $2.12(0.6)$ & $2.5(0.4)$ & $<0.001$ \\
\hline Total & $9.81(1.0)$ & $13.8(1.2)$ & \\
\hline
\end{tabular}

Values are presented as mean \pm standard deviation.

a)Derived from paired samples $t$-test.

mean $\mathrm{mJOA}$ recovery rate was $51.8 \%(\mathrm{SD}=13.1 \%)$, ranging from $23.0 \%$ to $88.8 \%$.

\section{Discussion}

This is the first report to measure disability in patients with CSM according to CNFDS and mJOA score with at least one year follow-up. The findings suggest that surgery for the treatment of patients with CSM is an efficacious procedure. It also indicates that the CNFDS and the $\mathrm{mJOA}$ tools have a strong correlation in measuring disability in patients with CSM at least one year follow-up.

Several authors reported clinical outcomes of decompressive surgery using the mJOA or the CNFDS score with a diverse range of research with successful outcome [17,18,22-27], which is in line with our findings. Clinical outcomes, such as modified JOA recovery rate, were assessed [28]; the mean mJOA recovery rate was $50.7 \% \pm 15.1 \%$ in elderly patients and $55.9 \pm 14.8$ in nonelderly patients one year after surgery, with no statistically significant differences evident between the two groups. The present results are similar.

Few studies have compared Nurick grading and mJOA score in evaluating functional disability and outcome in patients with CSM [15]. The studies assessed the correlation in a small number of cases or in patients undergo- ing different types of decompressive surgery [29]. They reported that the mJOA could be utilized in assessment of these patients. However, to the authors' best knowledge, relations between the mJOA score and the CNFDS score have not been studied before.

To evaluate CSM and disability for clinical or research purposes, a variety of measures can be used including the mJOA, and the JOACMEQ. The MJOA and the CNFDS score can be used to assess of patients with CSM. However, none of these instruments can be considered as a golden standard [17]. Accordingly, to identify ways to improve care, we need more specific measures for patient assessment. Additional research is needed to assess the discriminant power of the tools for specific diagnostic entities.

This study had some limitations. The sample size was small, and the follow-up period was short. More studies are recommended. For assessment of CSM, Kalsi-Ryan et al. [30] reviewed related articles to identify the most suitable measurement of the scoring systems as mJOA for CSM. They pointed out that these measurements do not objectively quantify the physical findings of the individual. In addition, they suggested that clinicians can obtain more reliable and quantitative information in the CSM population using ancillary measurements, such as the 30-meter walk test [30]. JOA recovery rate is a simple 
and useful parameter to compare clinical outcomes quantitatively. However, JOA recovery rate is not the gold standard and the use of this score may be unreasonable [28]. Finally, it is not clear that difference in preoperative and postoperative scores is an appropriate approach for clinical outcomes. Hence, there is a need to establish the definitive standard for assessment of clinical outcomes in patients with CSM.

\section{Conclusions}

Surgery for the treatment of patients with CSM is an efficacious procedure. CNFDS and the mJOA scores have a strong correlation in measuring disability among CSM patients. Disease-specific tools like the mJOA and the CNFDS could be used in the assessment of patients with CSM.

\section{Conflict of Interest}

No potential conflict of interest relevant to this article was reported.

\section{Acknowledgments}

The authors thank the staff of the Neurosurgery Unit Imam-Hossain Hospital, Tehran, Iran.

\section{References}

1. Binder AI. Cervical spondylosis and neck pain. BMJ 2007;334:527-31.

2. Vernon H. The Neck Disability Index: state-of-theart, 1991-2008. J Manipulative Physiol Ther 2008;31: 491-502.

3. Leak AM, Cooper J, Dyer S, Williams KA, TurnerStokes L, Frank AO. The Northwick Park Neck Pain Questionnaire, devised to measure neck pain and disability. Br J Rheumatol 1994;33:469-74.

4. Jordan A, Manniche C, Mosdal C, Hindsberger C. The Copenhagen Neck Functional Disability Scale: a study of reliability and validity. J Manipulative Physiol Ther 1998;21:520-7.

5. Bolton JE, Humphreys BK. The Bournemouth Questionnaire: a short-form comprehensive outcome measure. II. Psychometric properties in neck pain patients. J Manipulative Physiol Ther 2002;25:141-8.
6. Wheeler AH, Goolkasian P, Baird AC, Darden BV 2nd. Development of the Neck Pain and Disability Scale. Item analysis, face, and criterion-related validity. Spine (Phila Pa 1976) 1999;24:1290-4.

7. Westaway MD, Stratford PW, Binkley JM. The patient-specific functional scale: validation of its use in persons with neck dysfunction. J Orthop Sports Phys Ther 1998;27:331-8.

8. Benzel EC, Lancon J, Kesterson L, Hadden T. Cervical laminectomy and dentate ligament section for cervical spondylotic myelopathy. J Spinal Disord 1991;4:286-95.

9. Azimi P, Shahzadi S, Benzel EC, Montazeri A. Measuring motor, sensory and sphincter dysfunctions in patients with cervical myelopathy using the modified Japanese Orthopedic Association (mJOA) score: a validation stud. World Spinal Column J 202;3:91-7.

10. Azimi P, Rezaei O, Montazeri A. An outcome measure of functionality and quality of life in patients with cervical myelopathy. Iran Red Crescent Med J 2014;16:e8102.

11. Nurick S. The pathogenesis of the spinal cord disorder associated with cervical spondylosis. Brain 1972; 95:87-100.

12. Nurick $S$. The natural history and the results of surgical treatment of the spinal cord disorder associated with cervical spondylosis. Brain 1972;95:101-8.

13. Azimi P, Mohammadi HR, Montazeri A. An outcome measure of functionality and pain in patients with lumbar disc herniation: a validation study of the Japanese Orthopedic Association (JOA) score. J Orthop Sci 2012;17:341-5.

14. Chiles BW 3rd, Leonard MA, Choudhri HF, Cooper PR. Cervical spondylotic myelopathy: patterns of neurological deficit and recovery after anterior cervical decompression. Neurosurgery 1999;44:762-9.

15. Prolo DJ, Oklund SA, Butcher M. Toward uniformity in evaluating results of lumbar spine operations: a paradigm applied to posterior lumbar interbody fusions. Spine (Phila Pa 1976) 1986;11:601-6.

16. Herdmann J, Linzbach M, Krzan M, et al. The European myelopathy score. In: Baucher BL, Brock M, Klinger M, editors. Advances in neurosurgery. Berlin: Springer; 1994. p.266-8.

17. Nayeb Aghaei H, Azimi P, Shahzadi S, et al. Outcome measures of functionality, social interaction, and pain in patients with cervical spondylotic myelopathy: a 
validation study for the iranian version of the copenhagen neck functional disability scale. Asian Spine J 2015;9:901-8.

18. Vitzthum HE, Dalitz K. Analysis of five specific scores for cervical spondylogenic myelopathy. Eur Spine J 2007;16:2096-103.

19. Misterska E, Jankowski R, Glowacki M. Cross-cultural adaptation of the neck disability index and copenhagen neck functional disability scale for patients with neck pain due to degenerative and discopathic disorders: psychometric properties of the polish versions. BMC Musculoskelet Disord 2011;12:84.

20. Hirabayashi K, Satomi K. Operative procedure and results of expansive open-door laminoplasty. Spine (Phila Pa 1976) 1988;13:870-6.

21. Nunnally JC, Bernstein IH. Psychometric theory. New York: McGraw-Hill; 1994.

22. Yapali G, Gunel MK, Karahan S. The cross-cultural adaptation, reliability, and validity of the Copenhagen Neck Functional Disability Scale in patients with chronic neck pain: Turkish version study. Spine (Phila Pa 1976) 2012;37:E678-82.

23. Revanappa KK, Moorthy RK, Jeyaseelan V, Rajshekhar V. Modification of Nurick scale and Japanese Orthopedic Association score for Indian population with cervical spondylotic myelopathy. Neurol India 2015;63:24-9.

24. Ellingson BM, Salamon N, Woodworth DC, Holly
LT. Correlation between degree of subvoxel spinal cord compression measured with super-resolution tract density imaging and neurological impairment in cervical spondylotic myelopathy. J Neurosurg Spine 2015;22:631-8.

25. Nouri A, Tetreault L, Zamorano JJ, et al. Role of magnetic resonance imaging in predicting surgical outcome in patients with cervical spondylotic myelopathy. Spine (Phila Pa 1976) 2015;40:171-8.

26. Kose G, Hepguler S, Atamaz F, Oder G. A comparison of four disability scales for Turkish patients with neck pain. J Rehabil Med 2007;39:358-62.

27. Karpova A, Arun R, Davis AM, et al. Predictors of surgical outcome in cervical spondylotic myelopathy. Spine (Phila Pa 1976) 2013;38:392-400.

28. Son DK, Son DW, Song GS, Lee SW. Effectiveness of the laminoplasty in the elderly patients with cervical spondylotic myelopathy. Korean J Spine 2014;11:3944.

29. Revanappa KK, Rajshekhar V. Comparison of Nurick grading system and modified Japanese Orthopaedic Association scoring system in evaluation of patients with cervical spondylotic myelopathy. Eur Spine J 2011;20:1545-51.

30. Kalsi-Ryan S, Singh A, Massicotte EM, et al. Ancillary outcome measures for assessment of individuals with cervical spondylotic myelopathy. Spine (Phila Pa 1976) 2013;38:S111-22. 
Appendix 1. The Copenhagen Neck Functional Disability Scale.

\section{The Copenhagen Neck Functional Disability Scale}

\begin{tabular}{|c|c|c|c|}
\hline & Yes & Occasionally & No \\
\hline \multicolumn{4}{|l|}{ (1) Can you sleep at night without neck pain interfering? } \\
\hline \multicolumn{4}{|l|}{$\begin{array}{l}\text { (2) Can you manage daily activities without neck pain reducing activity } \\
\text { levels? }\end{array}$} \\
\hline \multicolumn{4}{|l|}{ (3) Can you manage daily activities without help from others? } \\
\hline \multicolumn{4}{|l|}{$\begin{array}{l}\text { (4) Can you manage putting on your clothes in the morning without taking } \\
\text { more time than usual? }\end{array}$} \\
\hline \multicolumn{4}{|l|}{$\begin{array}{l}\text { (5) Can you bend over the washing basin in order to brush your teeth } \\
\text { without getting neck pain? }\end{array}$} \\
\hline \multicolumn{4}{|l|}{ (6) Do you spend more time than usual at home because of neck pain? } \\
\hline \multicolumn{4}{|l|}{$\begin{array}{l}\text { (7) Are you prevented from lifting objects weighing from 2-4 kilograms } \\
\text { due to neck pain? }\end{array}$} \\
\hline \multicolumn{4}{|l|}{ (8) Have you reduced your reading activity due to neck pain? } \\
\hline \multicolumn{4}{|l|}{$\begin{array}{l}\text { (9) Have you been bothered by headaches during the time that you have } \\
\text { had neck pain? }\end{array}$} \\
\hline \multicolumn{4}{|l|}{ (10) Do you feel your ability to concentrate is reduced due to neck pain? } \\
\hline \multicolumn{4}{|l|}{$\begin{array}{l}\text { (11) Are you prevented from participating in your usual leisure time } \\
\text { activities due to neck pain? }\end{array}$} \\
\hline \multicolumn{4}{|l|}{ (12) Do you remain in bed longer than usual due to neck pain? } \\
\hline \multicolumn{4}{|l|}{$\begin{array}{l}\text { (13) Do you feel that neck pain has influenced your emotional relationship } \\
\text { with your nearest family? }\end{array}$} \\
\hline \multicolumn{4}{|l|}{$\begin{array}{l}\text { (14) Have you had to give up social contact with other people during the } \\
\text { past two weeks due to neck pain? }\end{array}$} \\
\hline (15) Do you feel that neck pain will influence your future? & & & \\
\hline
\end{tabular}

